\title{
Photocatalysis: A Novel Approach to Efficient Demulsification
}

\section{Baohui Wang, Di Gu, Lei Ji, Hongjun Wu}

Provincial Key Laboratory of Oil \& Gas Chemical Technology, College of Chemistry \& Chemical Engineering, Northeast Petroleum University, Daqing, Heilongjiang 163318, People's Republic of China

Corresponding author:

Baohui Wang

Provincial Key Laboratory of Oil \& Gas Chemical Technology

College of Chemistry \& Chemical Engineering

Northeast Petroleum University

Daqing

Heilongjiang 163318

People's Republic of China

Tel./fax: +86-0459-6503498

E-mail: wangbaohui60@163.com

\begin{abstract}
Using the theories of photocatalysis and emulsification, photocatalytic demulsification was introduced and studied for developing a direct method for destabilization and separation of oil-in-water emulsion. This was systematically investigated by photocatalysis and quiescent gravitational settling. The results demonstrated that the high demulsification efficiency directly correlated with photocatalysis. The photocatalytic effect and demulsifying enhancement have theoretically and experimentally been displayed and attributed to photocharge generation, redistribution of the self-oriented nano- $\mathrm{TiO}_{2}$, and photocatalytic oxidation of emulsifiers inside oil-water interface film under illumination. The extension of the classical photocatalysis is presented and effectively shifted to a novel process for practical demulsification.
\end{abstract}

Keywords: Photocatalysis; Demulsification; Emulsion; Titanium oxide 


\section{Introduction}

In order to reduce oil losses and water discharges, oil content has to be minimized in the aqueous phase by breaking up surfactant-stabilized emulsions. Demulsification is an important topic because of its effects on the environment and economy. Considerable effort has been made to develop effective treatment techniques, such as electrochemical demulsification, ${ }^{1,2}$ chemical demulsification, ${ }^{3,4}$ magnetic demulsification, ${ }^{5-7}$ and biological demulsification. ${ }^{8,9}$ Although these methods have been proven to be effective, processes involved in them, for example, heating and electrical methods, are expensive and energy intensive. ${ }^{10,11}$ Thus, it is necessary to develop an alternative method with properties including high oil removal rate and fast oil-water separation.

Photocatalysis has been extensively studied for many years. ${ }^{12-15}$ High-efficiency photooxidation has been reported in the literature for application in many fields. ${ }^{16,17}$ Our earlier work discovered that nanometer-sized $\mathrm{TiO}_{2}$ particles can be self-adsorbed and oriented onto oil-water interface of emulsions. ${ }^{18}$ Although the nano- $\mathrm{TiO}_{2}$ particles on the interface can be charged by UV treatment, reactive photoholes generated by photocatalysis primarily oxidize the oriented organic substances and damage the film between oil and water. At the same time, the surface-charged $\mathrm{TiO}_{2}$ particles alter the electrical balance of emulsions. Therefore, we report on a novel approach in this study that can achieve effective demulsification by efficient photocatalysis. The experimental results demonstrated that the high demulsifying capacity is correlated with photocatalysis of a model system emulsified by a typical molecule of sodium oleic acid. Because of its high efficiency and easy recovery of the photocatalyst, photocatalytic demulsification can be effectively used in many industrial areas with high performance.

\section{Experimental}

The photocatalyst used in this experiment was nano- $\mathrm{TiO}_{2}$ powder (P25, Degussa). X-ray diffraction (XRD) patterns estimated the diameter of the $\mathrm{TiO}_{2}$ particles as $12 \mathrm{~nm}$ in their major part of the anatase form. The photocatalysis measurements (Fig. 1) were carried out with a suspension and standstill system. A $125-\mathrm{W} \mathrm{Hg}$ lamp was used in the perpendicular direction for illuminating a quartz-graduated tube filled with emulsions.

Fig. 1. Schematic diagram of photocatalysis measurements

Deionized water and paraffin oil (technical grade) were used to prepare the emulsions at room temperature. A known amount of organic emulsifier (sodium oleic acid, AR grade) was first dissolved in deionized water to make a solution of $1.5 \%(\mathrm{~W} / \mathrm{W})$. This solution $(17 \mathrm{ml})$ and nano- $\mathrm{TiO}_{2}$ powder sometimes without the powder - were added to paraffin oil $(8 \mathrm{ml})$ in a $25-\mathrm{ml}$ measuring cylinder made of quartz. The emulsion was obtained by even mixing with a wrist-action shake of the cylinder at a constant speed. The $\mathrm{pH}$ of the deionized water was initially adjusted using $\mathrm{HCl}$ or $\mathrm{NaOH}$.

The ability and degree of demulsification were measured by a quiescent gravitational settling technique at room temperature. ${ }^{19}$ The prepared emulsions were allowed to cream several minutes for stability. The height of emulsion was recorded as the initial value. Then, they were settled in a still stand with or without illumination, such that the aqueous phase, oleic phase, and emulsion with $\mathrm{TiO}_{2}$ particles were creamed by gravitational settling. The volume of the emulsion layer (denoted by emulsion in Fig. 2) was recorded by measuring phase separation of quiescent settling at intervals. The type of emulsion was identified by combining dilution method and filter paper wetting method. ${ }^{20}$ Microscopic images were obtained from a computerized microscope (Olympus Corporation) for 
studying the microstructure of the emulsion. The emulsion sample was placed under a microscope to record the microstructural image, which was then recorded by a computer.

\section{Results and discussion}

On the basis of the theory of interface chemistry, the following three major mechanisms are possible for the stability of emulsions against phase separation: (1) steric stabilization due to the orderly arranged interfacial film between water and oil; (2) depletion stabilization due to the surface-charged film; and (3) structural stabilization due to the shape and viscosity of interfacial substances. In general, the interfacial film, which resists droplet coalescence, is a key factor that affects emulsion stability. Thus, a key to demulsification is to destroy the structure of the interfacial film between water and oil. The film consists of orderly arranged emulsifiers (e.g., surfactants, sometimes fine particles). A change or removal of the emulsifiers is an important route to demulsification.

In this experiment, water, paraffin oil, and sodium oleic acid were used to prepare the emulsion system From microscopic measurements and filter paper wetting methods, the emulsions were found to be stable, and to be of even diameter $(40-70 \mu \mathrm{m})$ and oil-in-water $(\mathrm{O} / \mathrm{W})$ type (for anatase, the water contact angle is $72^{\circ 13}$ ). Figures 2 and 3 depict microscopic images of the emulsion.

Fig. 2. Microscopic image of microstructure of emulsions $\left(\mathrm{O} / \mathrm{W}\right.$ emulsions by $1 \% \mathrm{TiO}_{2}+1.5 \%$ emulsifier without illumination)

Fig. 3. Microscopic image of microstructure of emulsions $\left(\mathrm{O} / \mathrm{W}\right.$ emulsions by $1 \% \mathrm{TiO}_{2}+1.5 \%$ emulsifier without illumination and an aggregation of $\mathrm{TiO}_{2}$ clusters, leading to the large particles in the figure)

It is evident from Fig. 2 that the external and internal phases are water and oil, respectively. The droplets are well distributed, existing stably for a long time. Microscopic image in Fig. 3 clearly shows the existence of the even and stable film with orderly arranged particles on the oil-water interface. Oil is trapped in the droplet by water. In other words, a film with an oriented arrangement was formed by adsorbing $\mathrm{TiO}_{2}$ particles and organic emulsifier molecules on the oil-water interface. Thus, the contact and interaction of $\mathrm{TiO}_{2}$ particles with organic emulsifiers favor a transition to photocatalysis.

Photocatalysis originates from photogenerated holes following the generation of electron-hole pairs on illumination of a semiconductor surface. This insolation means that (1) the photocatalyst particles are photocharged on the surface depending on the semiconductor type for the charge polarity and (2) strongly oxidizing species for oxidation exist nearby in organic compounds. These two actions favor the demulsification of emulsions. Figure 4 (A) shows photocatalytic demulsification in a model system of emulsions. Initially, the photo-demulsification yields a higher efficiency with illumination than without illumination. Thus, this effect correlates with the photocatalysis. The emulsion under illumination disappeared within $3 \mathrm{~h}$, which was stable for $27 \mathrm{~h}$ without illumination only by a gravitational settling. Then, the increase of emulsion stability for $1 \% \mathrm{TiO}_{2}$ indicates that the nanoparticles entered the interfacial films and stabilized the emulsions.

The effect of nano- $\mathrm{TiO}_{2}$ concentrations on photo-demulsification is shown in Fig. 4(B). The demulsification efficiency significantly depends on the volume of photocatalyst used. The high efficiency of degradation occurred monotonically in the concentrated photocatalyst. The contribution of the photocatalytic effect is evident. As shown in Fig. 4(C), the efficiency of photo-demulsification 
increases with a decrease of $\mathrm{pH}$ in the aqueous phase. This implies that the $\mathrm{TiO}_{2}$ particles are charged differently at different values of $\mathrm{pH}$. The phenomenon is explained in the following section.

Fig. 4. Curves of photocatalytic demulsification

According to the experimental results demonstrated above, a schematic diagram was proposed for illustrating the emulsion microstructure and photocatalytic mechanism (Fig. 5).

Fig. 5. Schematic diagram of emulsion microstructure and photocatalytic mechanism

The microstructure of emulsions consists of droplets dispersed in the continuous phase with oil and water as internal external phases, respectively (Figs. 2 and 3). The emulsifier molecules are ordered and situated on the interface for stabilizing the oil-water emulsion. Depending on the emulsifiers and conditions, the droplet surface is charged to form a static electric film against its coalescence. In general, emulsion droplets formed by sodium oleic acid (hydrophile-lipophile balance (HLB) value 17) are surrounded by a negative charge layer, which separates the droplets. The nano- $\mathrm{TiO}_{2}$ particles presented in the process involving contact with oil and water resulted in an ordered film formed by mixing the particles with emulsifier molecules (Fig. 3). The surface of $\mathrm{TiO}_{2}$ semiconductors (n-type) in contact with water are charged due to the self-produced electric field of the space charge film in darkness. The charged type originates from the $\mathrm{pH}$ value of contacted media. A $\mathrm{pH}$ value higher than that of $\mathrm{TiO}_{2}$ flat potential in water yields a negative surface charge, whereas a lower pH yields a positive surface charge on $\mathrm{TiO}_{2}$ in water. In this case, a negative charge film $\left(\mathrm{TiO}_{2}\right)$ was added to the interface, which favors the stability of emulsions without illumination (black line in Fig. 4A) and demulsion with illumination (blue line in Fig. 4C).

An important parameter in the photocatalytic reactions taking place on particulate surfaces is the $\mathrm{pH}$ of the solution, as it dictates the surface charge properties of the photocatalyst and size of aggregates it forms. ${ }^{21}$ On the basis of the recent update of the point of zero charge (pzc) by Kosmulski, ${ }^{22}$ Degussa P25 has been reported to have pzc 6.9. Under acidic or alkaline condition, the surface of $\mathrm{TiO}_{2}$ can be protonated or deprotonated according to Eqs. (1) and (2), respectively ${ }^{23}$ :

$\mathrm{TiOH}+\mathrm{H}^{+} \rightarrow \mathrm{TiOH}_{2}^{+}$

$\mathrm{TiOH}+\mathrm{OH}^{-} \rightarrow \mathrm{TiO}^{-}+\mathrm{H}_{2} \mathrm{O}$

The $\mathrm{TiO}_{2}$ surface will remain positively charged in an acidic medium $(\mathrm{pH}<6.9)$ and negatively charged in an alkaline medium $(\mathrm{pH}>6.9)$. The photocatalytic reaction is affected by $\mathrm{pH}$ (proton) with varying efficiency. ${ }^{21-25}$ In general, $\mathrm{pH}$ dominates the redox reaction by the generation of $\bullet \mathrm{OH}$ from the $\mathrm{OH}^{-}$and absorption of the reactants on the $\mathrm{TiO}_{2}$ surface. On the one hand, more $\cdot \mathrm{OH}$, which is the controlling factor for the reaction, were produced by $\mathrm{OH}^{-}$with the increase of $\mathrm{pH}$, which, in turn, benefit the photooxidation of $\mathrm{RCH}_{2} \mathrm{COO}^{-}$. On the other hand, more $\mathrm{RCH}_{2} \mathrm{COO}^{-}$will be adsorbed on $\mathrm{TiO}_{2}$ surface with the increase of $\mathrm{pH}$, and the reduction of active sites will lead to a decrease in the amount of $\bullet \mathrm{OH}$. Therefore, a suitable $\mathrm{pH}$ yields a high rate of redox reaction.

The results presented above illustrated that the photocatalytic demulsification is decidedly attributed to the photocharges and redox reaction on the $\mathrm{TiO}_{2}$ surfaces, the two ways that charge redistribution and redox reaction between $\mathrm{TiO}_{2}$ and emulsifier occur simultaneously under illumination. Thus, it can be observed from Fig. 4C that a pH of 5.5 achieves the fastest demulsification efficiency, but if the time is long enough, the final demulsification efficiency is approximately equal. In this study, 
more protons are in favor of the photocharges and redox reaction.

Under illumination, absorption of the near-UV light by nano- $\mathrm{TiO}_{2}$ in the interface at $\lambda<385 \mathrm{~nm}$ is followed by the generation of electron $\left(\mathrm{e}^{-}\right)$-hole $\left(\mathrm{h}^{+}\right)$pairs. By the self-produced electric field, these holes can inject and charge the surface of $\mathrm{TiO}_{2}$ particles where they are ultimately poised and undergo redox chemistry with suitable substances. Thus, the trapped holes can react with $\mathrm{H}_{2} \mathrm{O}$ to produce $\cdot \mathrm{OH}$, or react with surface-adsorbed organic substances to produce organic radical species. The electrons can react with chemisorbed $\mathrm{O}_{2}$ to produce $\mathrm{O}_{2} \bullet$ radical species. In this case, the positive photocharging results in a reduction of the surface charges of emulsions and selective degradation of the contacted organic emulsifiers via the oxidizing species because of the easy photooxidation of $\mathrm{RCH}_{2}-\mathrm{COO}^{-}{ }^{26-27}$ The possible mechanism of photooxidation of emulsifiers $\left(\mathrm{RCH}_{2}-\mathrm{COO}^{-}\right)$is shown in Eqs. (3)-(12):

$\mathrm{TiO}_{2}+\mathrm{hv} \rightarrow \mathrm{h}^{+}+\mathrm{e}^{-}$

$\mathrm{h}^{+}+\mathrm{H}_{2} \mathrm{O} \rightarrow \mathrm{H}^{+}+\cdot \mathrm{OH}$

$\mathrm{O}_{2}+\mathrm{e}^{-} \rightarrow \cdot \mathrm{O}_{2}^{-}$

$\cdot \mathrm{O}_{2}^{-}+\mathrm{H}^{+} \rightarrow \cdot \mathrm{OOH}$

$\mathrm{RCH}_{2} \mathrm{COOH} \rightarrow \mathrm{RCH}_{2} \mathrm{COO}^{-}+\mathrm{H}^{+}$

$\mathrm{RCH}_{2} \mathrm{COO}^{-}+\bullet \mathrm{OH} \rightarrow \mathrm{RCH}_{2} \bullet+\mathrm{CO}_{2}+\mathrm{OH}^{-}$

$\mathrm{RCH}_{2} \mathrm{COO}^{-}+\mathrm{h}^{+} \rightarrow \mathrm{RCH}_{2} \bullet+\mathrm{CO}_{2}$

$\mathrm{RCH}_{2} \bullet+\mathrm{O}_{2} \rightarrow \mathrm{RCH}_{2} \mathrm{OO} \bullet$

$\mathrm{RCH}_{2} \mathrm{OO} \bullet+\cdot \cdot \mathrm{OOH} \rightarrow \mathrm{RCH}_{2} \mathrm{OOOOH}$

$\mathrm{RCH}_{2} \mathrm{OOOOH}+\mathrm{RCH}_{2} \mathrm{COOH} \rightarrow \mathrm{RCH}_{2} \mathrm{OH}+\mathrm{RCHO}+\mathrm{O}_{2}+\mathrm{CO}_{2}$

\section{Conclusions}

In order to achieve demulsification, the interfacial film was discharged electrically and destroyed simultaneously. More work on this topic is ongoing in our laboratory to gain a better understanding of the basic mechanism involved.

Although the method is demonstrated in this study for one model surfactant linked with $\mathrm{COO}^{-}$ base, it can be easily extended to other types (anionic or cationic) of surfactants, because they had been achieved by photocatalytic oxidation. ${ }^{28-30}$ In addition, the high efficiency and easy recovery of catalyst make photocatalytic demulsification a promising method that can be used in many industrial areas.

\section{Acknowledgments}

This study is financially supported by the National Science Foundation of China (Grant No. 21376049).

\section{References}

[1] H.Z. Ma, B. Wang, Electrochemical pilot-scale plant for oil field produced wastewater by M/C/Fe electrodes for injection, J. Hazard. Mater. 132 (2006) 237-243.

[2] B.K. Körbahti, K. Artut, Electrochemical oil/water demulsification and purification of bilge water using Pt/Ir electrodes, Desalination 258 (2010) 219-228.

[3] A.A. Hafiz, H.M. El-Din, A. M. Badawi, Chemical destabilization of oil-in-water emulsion by novel polymerized diethanolamines, J. Colloid Interface Sci. 284 (2005) 167-175.

[4] M. Nikkhah, T. Tohidian, M.R. Rahimpour, A. Jahanmiri, Efficient demulsification of water-in-oil emulsion by a novel nano-titania modified chemical demulsifier, Chem. Eng. Res. Des. 94 (2015) 
$164-172$.

[5] J. Liang, N. Du, S. Song, W. Hou, Magnetic demulsification of diluted crude oil-in-water nanoemulsions using oleic acid-coated magnetite nanoparticles, Colloid. Surface. A 466 (2015) $197-202$.

[6] Y. Chen, X. Lin, N. Liu, Y. Cao, F. Lu, L. Xu, L. Feng, Magnetically Recoverable Efficient Demulsifier for Water-in-Oil Emulsions, ChemPhysChem 16 (2015) 595- 600.

[7] S. Li, N. Li, S. Yang, F. Liu, J. Zhou, The synthesis of a novel magnetic demulsifier and its application for the demulsification of oil-charged industrial wastewaters, J. Mater. Chem. A 2 (2014) 294-99.

[8] X.F. Huang, J. Liu, L.J. Lu, Y. Wen, J.C. Xu, D.H. Yang, Q. Zhou, Evaluation of screening methods for demulsifying bacteria and characterization of lipopeptide bio-demulsifier produced by Alcaligenes sp., Bioresour. Technol. 100 (2009) 1358-1365.

[9] H. Salehizadeh, A. Ranjbar, K. Kennedy, Demulsification capabilities of a Microbacterium species for breaking water-in-crude oil emulsions, Afr. J. Biotechnol. 12 (2013) 2019-2026.

[10] A.A. Pena, G.J. Hirasaki, C.A. Miller, Chemically Induced Destabilization of Water-in-Crude Oil Emulsions, Ind. Eng. Chem. Res. 44 (2005) 1139-1149.

[11] S.S. Wang, C.J. Lee, C.C. Chan, Demulsification of Water-in-Oil Emulsions by Use of a High Voltage ac Field, Sep. Sci. Technol. 29 (1994) 159-170

[12] A. Fujishima, K. Honda, Electrochemical Photolysis of Water at a Semiconductor Electrode, Nature. 238 (1972) 37-38.

[13] A. Kudo, Y. Miseki, Heterogeneous photocatalyst materials for water splitting, Chem. Soc. Rev. 38 (2009) 253-278.

[14] A. Kubacka, M.F. García, G. Colon, Advanced Nanoarchitectures for Solar Photocatalytic Applications, Chem. Rev. 112 (2012) 1555-1614.

[15] D. Gu, H. Wu, Y. Zhu, B. Wang, Modified hierarchical $\mathrm{TiO}_{2} \mathrm{NTs}$ for enhanced gas phase photocatalytic activity, RSC Adv. 5 (2015) 57937-57942

[16] U. Diebold, The surface science of titanium dioxide, Surf. Sci. Rep. 48 (2003) 53-229.

[17] J. Schneider, M. Matsuoka, M. Takeuchi, J. Zhang, Y. Horiuchi, M. Anpo, D.W. Bahnemann, Understanding $\mathrm{TiO}_{2}$ Photocatalysis: Mechanisms and Materials, Chem. Rev.114 (2014) 9919- 9986.

[18] B. Wang, Emulsive ProPerties of nanometer $\mathrm{TiO}_{2}$ ultrafine Powder in oil-water system, Chinese Sci. Bull. 42 (1997) 2237-2237.

[19] P. Becher, Encyclopedia of Emulsion Technology, Marcel Dekker, New York, 1983.

[20] P. Becher, Emulsions: Theory and Practice, Reinhold, New York, 1965.

[21] M.M. Haque, M. Muneer, Photodegradation of norfloxacin in aqueous suspensions of titanium dioxide,J. Hazard. Mater. 145 (2007) 51-57.

[22] M. Kosmulski, pH-dependent surface charging and points of zero charge:III. Update, J. Coll. Inter. Sci. 298 (2006) 730-741.

[23] U.I. Gaya, A.H. Abdullah, Heterogeneous photocatalytic degradation of organic contaminants over titanium dioxide: A review of fundamentals, progress and problems. J. Photoch. Photobio. C 9 (2008) 1-12.

[24] J. Sun, X.Wang, J. Sun, R. Sun, S. Sun, L. Qiao, Photocatalytic degradation and kinetics of 
Orange G using nano-sized Sn(IV)/TiO $/ \mathrm{AC}$ photocatalyst, J. Mol. Catal. A. 260 (2006) 241-246.

[25] J.F. Montoya, M.F. Atitar, D.W. Bahnemann, J. Peral, P. Salvador, Comprehensive Kinetic and Mechanistic Analysis of $\mathrm{TiO}_{2}$ Photocatalytic Reactions According to the Direct-Indirect Model: (II) Experimental Validation, J. Phys. Chem. C 118 (2014) 14276-14290.

[26] J. Schwitzgebel, J.G. Ekerdt, H. Gerischer, A. Heller, Role of the Oxygen Molecule and of the Photogenerated Electron in $\mathrm{TiO}_{2}$-Photocatalyzed Air Oxidation Reactions, J. Phys. Chem. 99 (1995) 5633-5638.

[27]M. Pelaez, N. T. Nolan, S.C. Pillai, M.K. Seery, P. Falaras, A.G. Kontos, P.S.M. Dunlop, J.W.J. Hamilton, J.A. Byrne, K. O'Shea, M.H. Entezari, D.D. Dionysiou, A review on the visible light active titanium dioxide photocatalysts for environmental applications, Appl. Catal. B 125 (2012) 331-349.

[28] S. Naya, T. Nikawa, K. Kimura, H. Tada, Rapid and Complete Removal of Nonylphenol by Gold Nanoparticle/Rutile Titanium(IV) Oxide Plasmon Photocatalyst, ACS Catal. 3 (2013) 903-907.

[29] H. Dzinun, M.H.D. Othman, A.F. Ismail, M.H. Puteh, M.A. Rahman, J. Jaafar, Photocatalytic degradation of nonylphenol by immobilized $\mathrm{TiO}_{2}$ in dual layer hollow fibre membranes, Chem. Eng. J. 269 (2015) 255-261.

[30] X.H. Lin, D. Sriramulu, S.F.Y. Li, Selective removal of photocatalytic non-degradable fluorosurfactants from reverse osmosis concentrate, Water Res. 68 (2015) 831-838. 


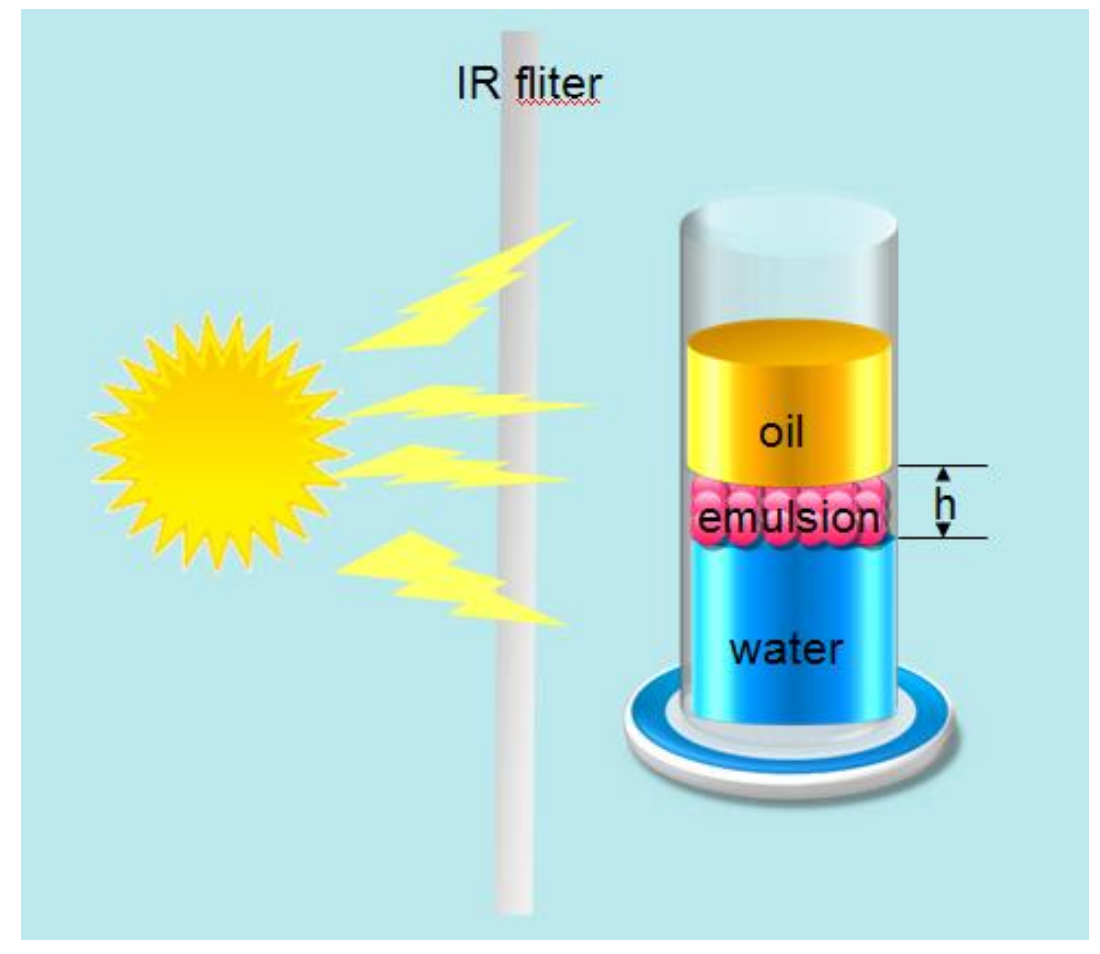

Fig.1 Schematic diagram of photocatalysis measurements 


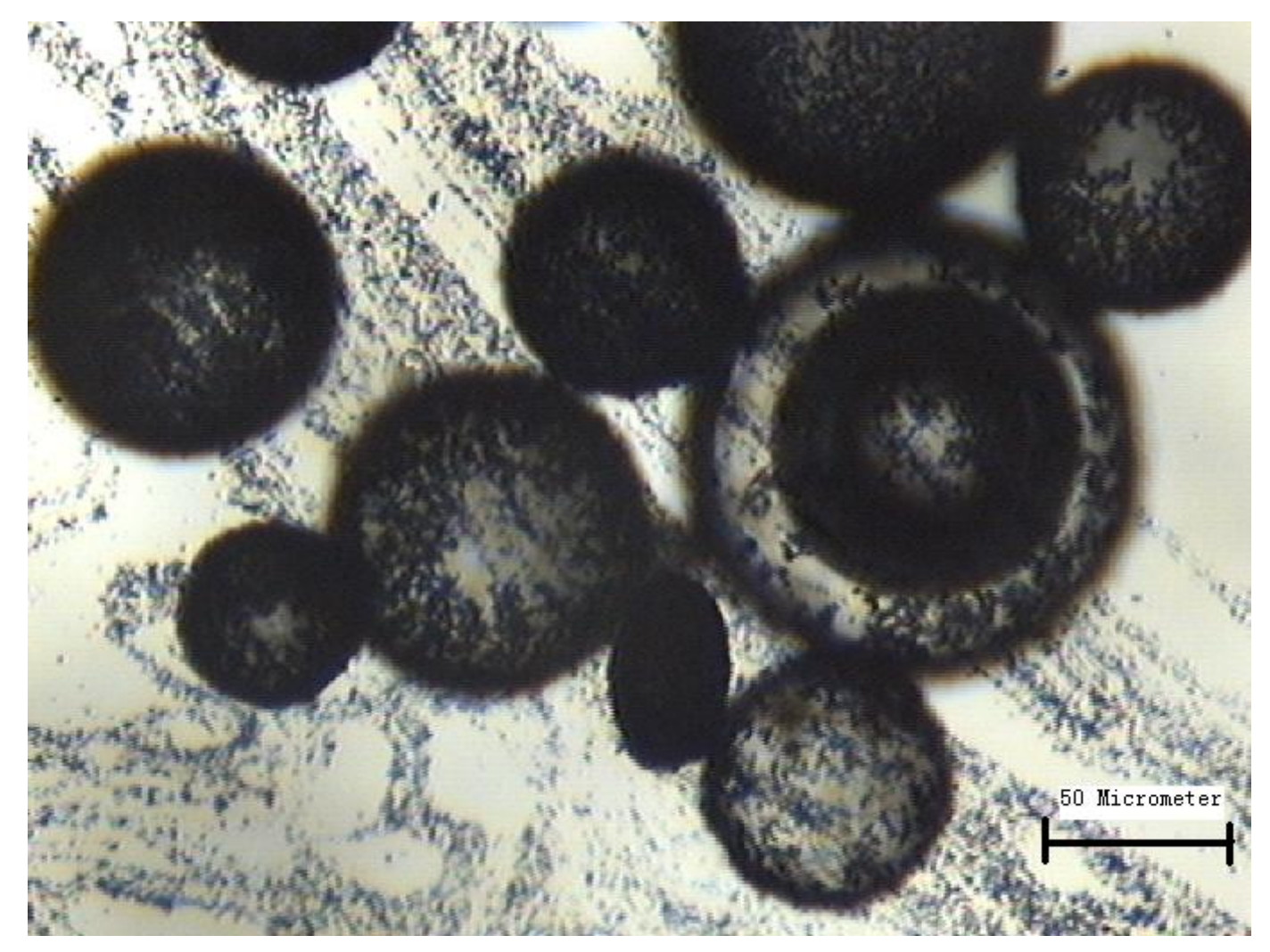

Fig. 2 Microscopic image of microstructure of emulsions (O/W emulsions by $1 \% \mathrm{TiO}_{2}+1.5 \%$ emulsifier in absence of illumination) 


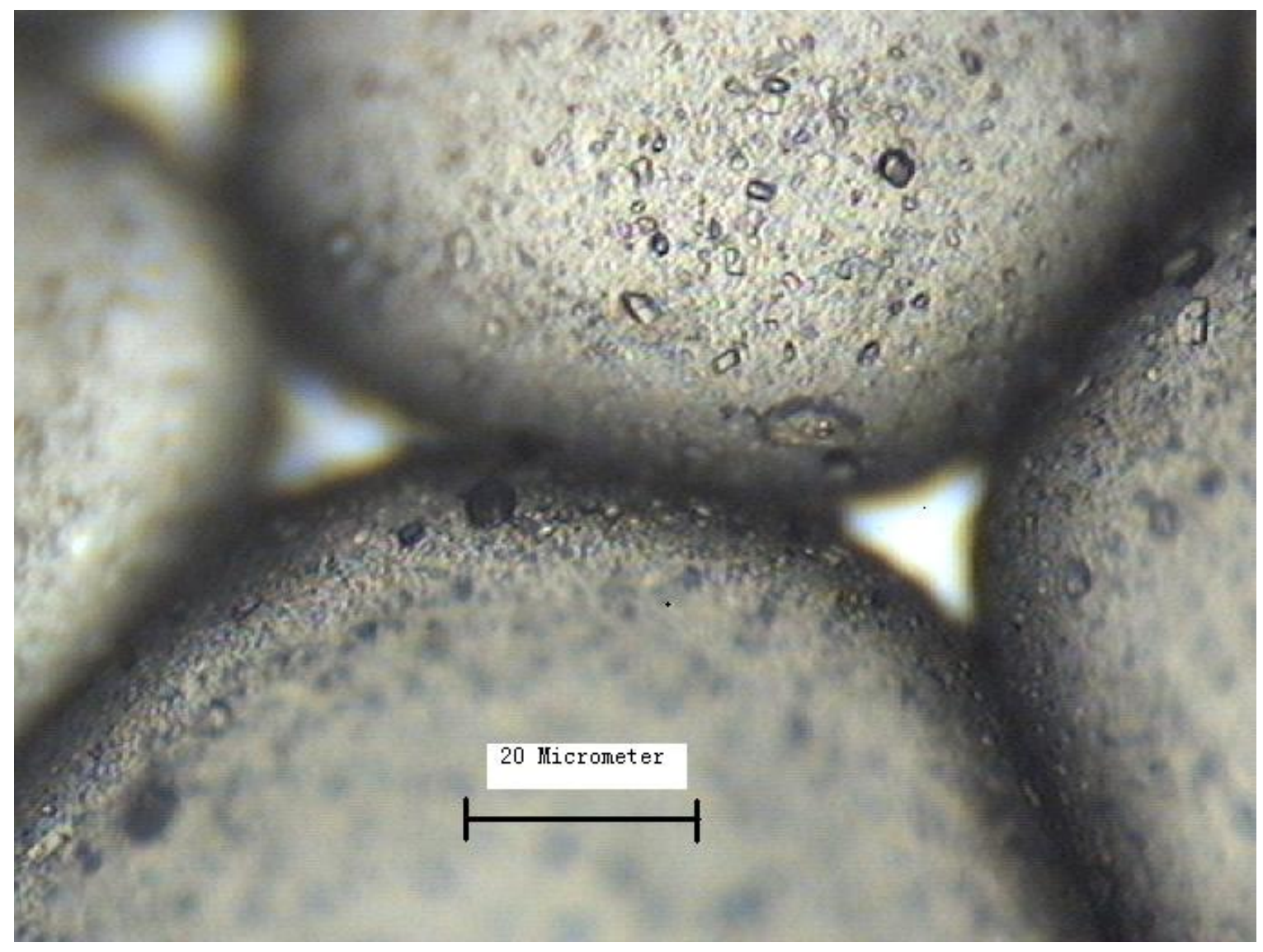

Fig. 3 Microscopic image of microstructure of emulsions (O/W emulsions by $1 \% \mathrm{TiO}_{2}+1.5 \%$ emulsifier in the absence of illumination and an aggregation of $\mathrm{TiO}_{2}$ clusters leading to the large particles in the figure) 


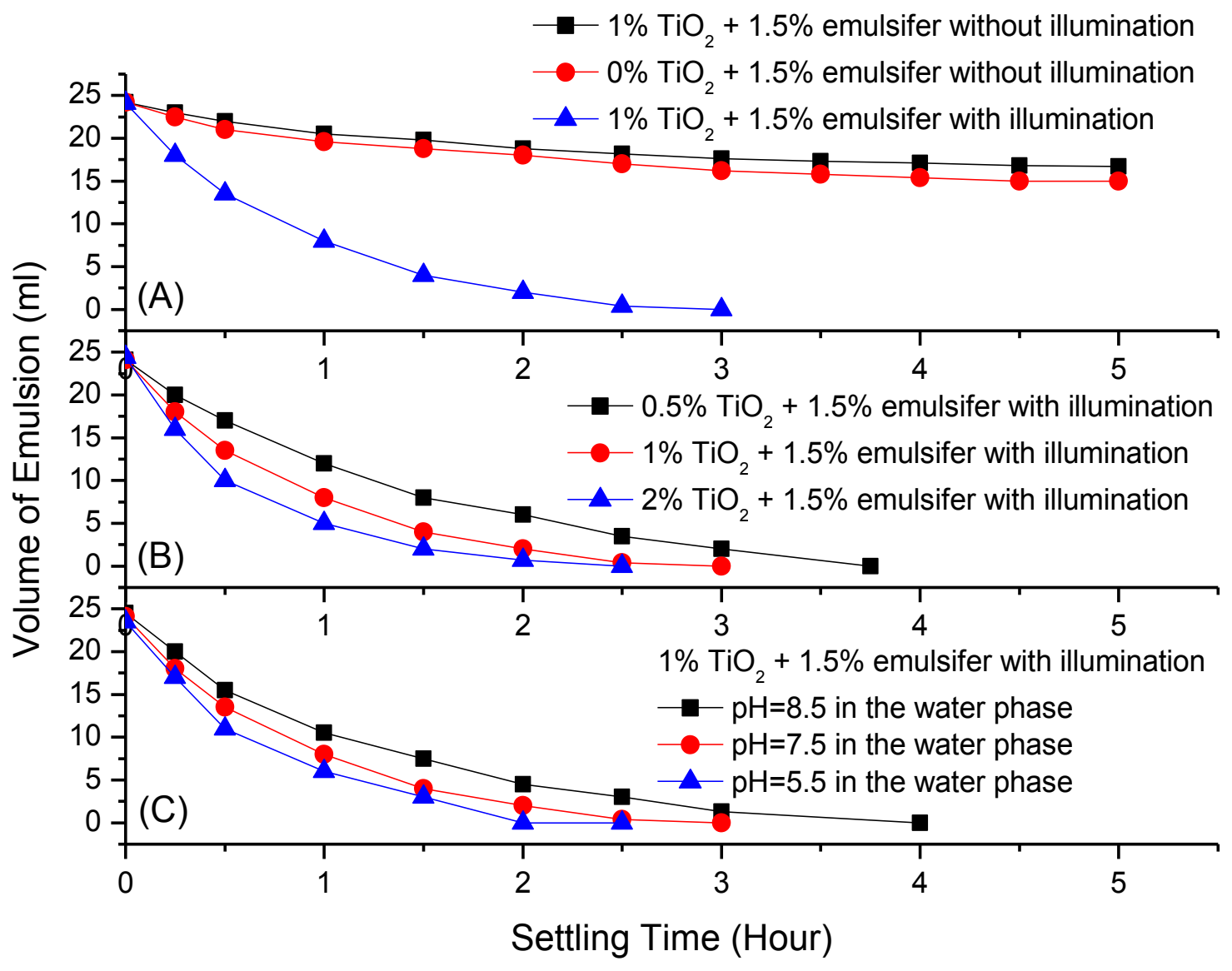

Fig. 4 Curves of the photocatalytic demulsification 


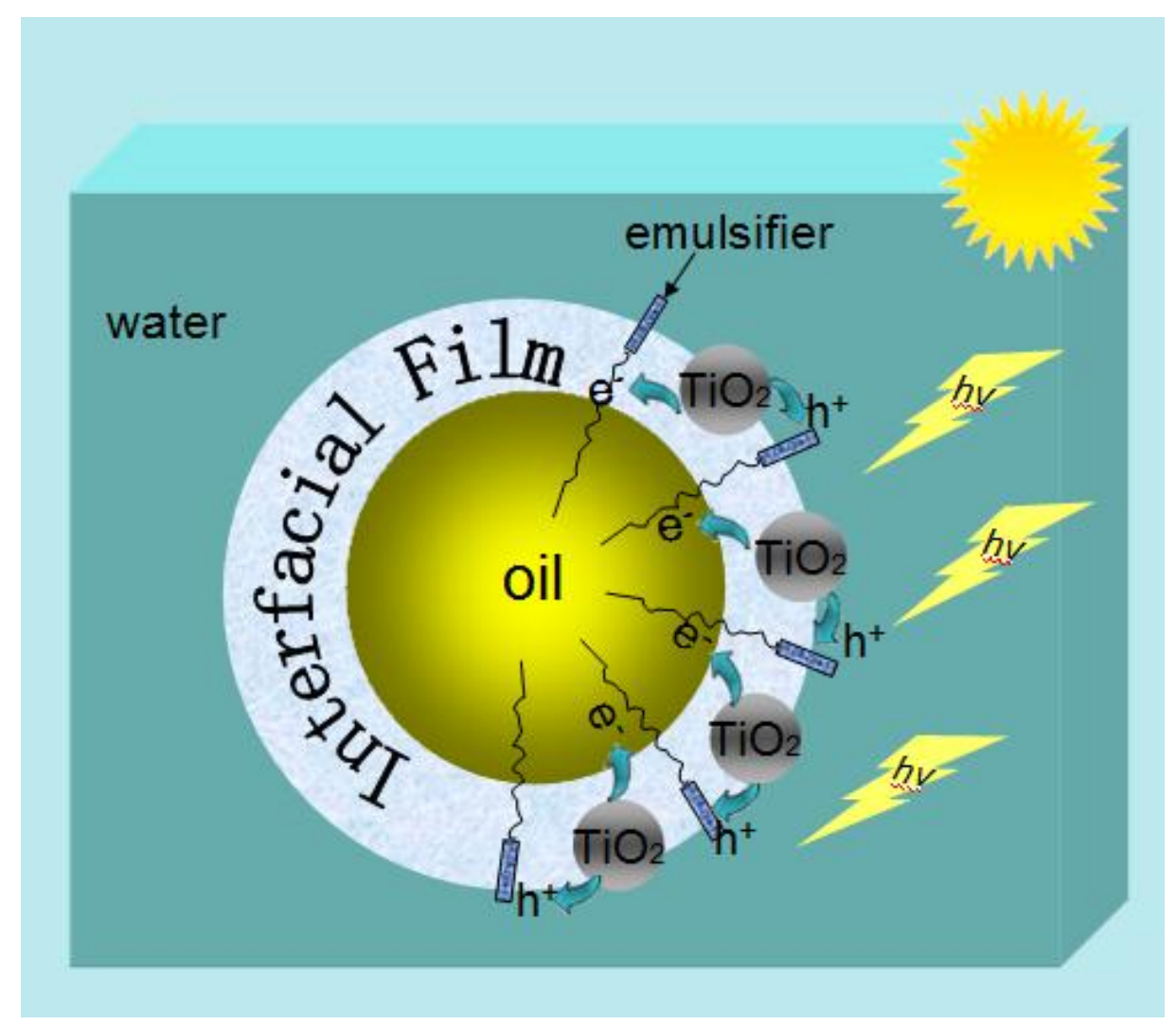

Fig.5 Schematic diagram of emulsion microstructure and photocatalytic mechanism 
Graphical abstract

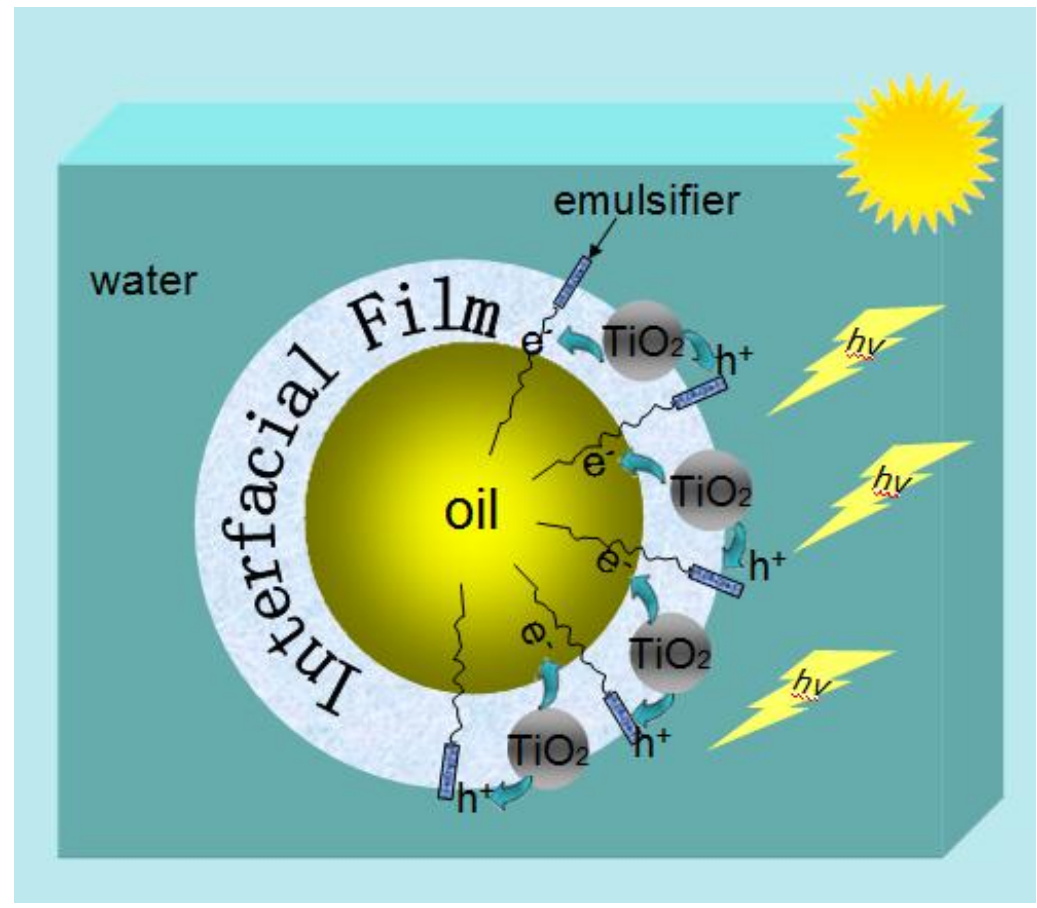

Schematic diagram of emulsion microstructure and photocatalytic mechanism 